\title{
Hierarchical structures of anodized cold gas sprayed titanium coatings
}

A. M. Vilardell*, N. Cinca, I. Pacheco, C. Santiveri, S. Dosta, I.G.Cano, J. M. Guilemany, M. Sarret, C. Muller

Centro de Proyección Térmica (CPT) Dpt. Material Science and Physical Chemistry. Universitat de Barcelona. c/Martí i Franqués 1, 08028 Barcelona, Spain. *Corresponding author: amvilardell.research@gmail.com

\begin{abstract}
Cold Gas Spray (CGS) titanium coatings have been produced to obtain porous and rough titanium coatings with enhanced mechanical performance. The optimal spraying conditions reached values up to $40 \mathrm{MPa}$ of tensile strength, $39 \mathrm{MPa}$ of shear strength and a loss mass of $37 \mathrm{mg} / 100$ cycles in abrasive test, values in accordance with the ASTM standards to be applied for orthopedic joint prostheses. An innovative hierarchical structure (micro-nano) consisted of a $\mathrm{TiO}_{2}$ nanotubes top layer obtained by anodization onto CGS Ti coating. The present paper focuses on the characterization of both surfaces, as-sprayed CGS Ti layer and double $\mathrm{Ti}^{-\mathrm{TiO}} \mathrm{O}_{2}$ layer, in terms of mechanical properties, surface topography and wettability (contact angle). Not significant changes in micro-roughness, $\mathrm{Ra} \sim 40 \mu \mathrm{m}$ and $\mathrm{Ra} \sim 30 \mu \mathrm{m}$, but a significant decrease of contact angle, from $\approx 26^{\circ}$ up to $0^{\circ}$, were observed between these two structures. This behavior indicates that the combination of the CGS+anodizing results in promising high rough superhydrophilic surfaces, ideal for biomedical applications.
\end{abstract}

Keywords: coatings, thermal spray, anodization, nanotubes, roughness, wettability.

\section{Introduction}

Titanium is one of the metals that has been quite largely studied for its deposition by the solid-state coating process, Cold Gas Spray (CGS), due its potential in aeronautical and aerospace industry [1] as well as anodic protection in corrosive environments [2] and in dimensional restoration and repair fields. These applications mainly require the formation of dense coatings. Regarding the use of the CGS technology, this has been quite easy for ideal 
materials, i.e. those with relatively low melting points, high densities, low mechanical strength and low heat capacities such as $\mathrm{Zn}$ and $\mathrm{Cu}$; for others, more expertise and development has been needed. In the titanium case, it has been influenced by: (i) its high strength to weight ratio but relative low deformability due to its hexagonal close-packed crystal structure, (ii) the noticeable flow stress rate sensitivity and strain hardening at high strain rates, (iii) low thermal softening sensitivity and, (iv) the disruption of oxide layers to promote metallurgical contacts [3]. Dense coatings could be achieved with small sized particles $(16 \mu \mathrm{m})$ using helium gas [4]. Nevertheless, this is still quite a challenge when using nitrogen whatever the particle size is, as lower particle velocities are reached in comparison with helium gas. Actually, it has been mostly observed the formation of a gradual increasing porosity from the inner part of the coatings to the outer part due to the lower tamping effect of the top-layer [5].

However, a porous titanium coating could be quite useful in biomedical applications. In this case, the final application would demand for a different microstructure. The strategy here used for such purpose has been employing large sized irregular particles. Van Steenkiste et al., [6] used a new nozzle configuration to be able to successfully deposit aluminum particles in the range between 63 and $106 \mu \mathrm{m}$, but in their case, to obtain dense coatings. Using coarse particles to produce porous coatings is easier than using small particles due to their lower velocities and wider gaps to be filled between the deposited particles during spraying. In addition, large dimensions involve lower cooling rates as well as lower strainrates and thus lower strain-rate hardening. All these facts, considering also the low thermal diffusivity of titanium which facilitates the local retention of interfacial heating, may favor the occurrence of shear instabilities and, therefore, better bonding at the contact points; the formation of adiabatic shear instabilities has been reported to be the mostly accepted bonding mechanism in CGS [7]. 
Commercial joint prosthesis currently uses the Vacuum Plasma Spray (VPS) technology to produce porous coatings in total hip and knee arthroplasty $[8,9,10]$. VPS is an extended technology that enables the spraying of oxygen and high temperature-sensitive metals; this is why it has been used for spraying titanium avoiding oxidation and enabling its use for biomedical applications. As an alternative, some studies have approached recently the CGS technology, which is a process where there is not any heat source from combustion or electrical arc discharge. Rather, the high kinetic energy of the particles given by a heated accelerated gas, make them to plastically deform and typically create a metallurgical bond at the contact interfaces. Since the bonding mechanisms are different, with the biomedical application in mind, the specific mechanical requirements need to be accomplished in order to make sure that the minimum values are surpassed for that industry.

Hierarchical structures consisting of micro- and nanostructured surfaces have been investigated for their effects on cell activities [11]. Surface microstructures mainly contribute on the mechanical fixation as well as long-term stability of the implant. The surface roughness and open porosity play a key role in the in vivo interaction. From one hand, the achievement of porous surfaces by thermal spraying is a versatile system that offers an offthe-shelf solution for various problems, including aseptic loosening, infections, periprosthetic fractures, and instability. It has been well demonstrated that cells show a high sensitivity to surface roughness at the micro and nanoscale level $[12,13,14,15,16]$. Surface nanofeatures have demonstrated to improve protein and cell adhesion, thus enhancing ossointegration and promoting bone ingrowth [17]. One of the treatments to improve the bioactivity of the prosthesis is by performing an anodizing, which has been actually mostly applied to dental implants [18]. Several studies have revealed considerable impact of $\mathrm{TiO}_{2}$ nanotubes (NTs) surfaces on osteoblast differentiation $[19,20]$ as well on proliferation and subsequent 
mineralization of extracellular matrix [21], which makes such surfaces ideal for their use in orthopaedic applications.

The present paper suggests the combination of the two strategies CGS+anodizing in order to produce hierarchical structures with different surface topographies. Xie et al. [22] performed an anodization of VPS Ti coatings deposited on Ti-6Al-4V alloy substrates, and found higher cell adhesion quantity (about 30\% more) on the hierarchical structure than that on the as-sprayed VPS coatings. The anodizing on titanium surfaces can also have other influences and it has been investigated in the biomedical field in terms of their antibacterial properties $[23,24]$, drug delivery [25,26] systems and cell viability [19,21], due to their simple fabrication and also their appropriate biological response.

In view of the overall above considerations, the present work is aimed twofold: (i) perform the mechanical characterization of the as-sprayed porous CGS Ti coatings in order to verify it as an alternative to VPS and (ii) perform an evaluation of the surface topography and wettability compared to the double process CGS+anodizing in order to elucidate the micro/nano features that might influence the cell attachment.

\section{Materials and methods}

Irregular coarse commercial pure $\mathrm{Ti}(\mathrm{CP}-\mathrm{Ti})$ powder was used to obtain rough surfaces by CGS. Grade 5 Ti6Al4V alloy $(20 \times 50 \times 5 \mathrm{~mm})$ from Technoalloy (Spain). Previous to spraying, Ti6A14V alloy substrates were grinded with \#240 grade SiC paper and cleaned with ethanol in ultrasounds bath. The CGT KINETICS® 4000 (Cold Gas Technology, Ampfing, Germany) was used in order to produce the rough titanium coatings, with a maximum operating gas pressure of 40 bars and gas temperature of $800{ }^{\circ} \mathrm{C}$; nitrogen was used as the propellant gas. The cross-section sample was prepared by grinding and polishing until $1 \mu \mathrm{m}$ size diamond suspension. 
The spraying conditions were optimized under the criteria to obtain a high roughness and high coating adhesion [27]. The cross-section area was prepared by grinding and polishing samples until $1 \mu \mathrm{m}$ size diamond suspension. Thickness values were measured according to ASTM F1854 with Optical Microscopy (Leica DMI5000 M) and surface topography with Confocal Microscopy (Leica DCM3D).

The optimal CGS CP-Ti coating was characterized according to standard specifications ASTM F-2068 (2015), ASTM F-2083 (2012), ASTM F-1378 (2012) (Femoral, total knee and shoulder prostheses respectively). The standard test method for the evaluation of tensile strength of the rough CGS CP-Ti coatings was applied following ASTM F-1147 using Servosis ME-402/10 model equipment with a strain rate of $0.02 \mathrm{~mm} / \mathrm{s}$ which was controlled by position until failure occurs. The test consists of gluing a cylindrical coated specimen with a resin to an uncoated sand-blasted specimen. Shear testing was applied following ASTM F-1044, by using a Shimadzu AG-IS $50 \mathrm{KN}$ model equipment with a constant speed of $0.25 \mathrm{~cm} / \mathrm{min}$ until failure. This test consists of gluing a cylindrical coated specimen with a resin to an uncoated sand-blasted specimen. Free and fracture surfaces were examined by Scanning Electron Microscopy (SEM); using a JEOL 5510 operated at $20 \mathrm{kV}$. and equipped with an Energy Dispersive Spectroseopy (EDS) for microanalysis.

Abrasion measurements were performed by using a 5135 model taber rotary platform abrasion tester following the standard specification ASTM F-1978, with H-22 Calibrade Vitrified Clay and Abrasive grain wheel and $250 \mathrm{~g}$ mass of the abrading head without added weight during 100 cycles. The specimens were weighed before and after being tested in order to measure the mass loss.

The anodization step was performed on the as-sprayed CGS CP-Ti coatings and 99.7\% titanium foils of 0.25 or $2 \mathrm{~mm}$ thick (Sigma Aldrich) in a two electrode configuration cell using a DELTA ELEKTRONIKA SM 400-AR-4 power supply, controlled by LabVIEW. An 
AA304 stainless steel foil was used as auxiliary electrode. A Ethylene glycol bath with 2,5/5 wt $\% \mathrm{H}_{2} \mathrm{O}$ and $0.25 / 0.5 \mathrm{wt} \% \mathrm{NH}_{4} \mathrm{~F}$ was used. In the anodization process, 30 to $60 \mathrm{~V}$ were applied at different anodizing times.

Coating morphology was analyzed with a JEOL JSM 5310 SEM or a Field Emission Scanning Electron Microscope (FE-SEM) JEOL JSM-7100F. The CP-Ti powder and the coating were analyzed by X-Ray Diffraction (XRD) using a X'Pert PRO MPD diffractometer (PANalytical). The surface composition of the CGS CP-Ti coating was investigated by X-ray Photoelectron Spectroscopy (XPS) using a PHI 5500 Multitechnique System (from Physical Electronics) with a monochromatic X-ray source (Aluminum Ka line of $1486.6 \mathrm{eV}$ energy and $350 \mathrm{~W}$ ), placed perpendicular to the analyzer axis and calibrated using the $3 \mathrm{~d} 5 / 2$ line of $\mathrm{Ag}$ with a full width at half maximum (FWHM) of $0.8 \mathrm{eV}$. A home-made water contact angle goniometer with ImageJ software program has been used to the measurement of the contact angles, performing static measurements after 10 s in sessile drop mode with $2 \mu$ l volume MilliQ $\mathrm{H}_{2} \mathrm{O}$ droplet.

\section{Results}

\subsection{Cold Gas Sprayed coating}

Figure 1 shows a schematic illustration of the parts that can be coated by porous titanium on femur prosthesis (general view of a typical commercial prosthesis with a titanium porous coating), together with the top surface morphology and the cross section of the proposed CP-Ti coatings obtained by CGS. A quite abrupt topography can be observed providing an enhancement of specific surface with a coating thickness of of $294 \pm 75 \mu \mathrm{m}$. Moreover, good bonding interface could be observed between coating and substrate in which delamination was not perceived. 


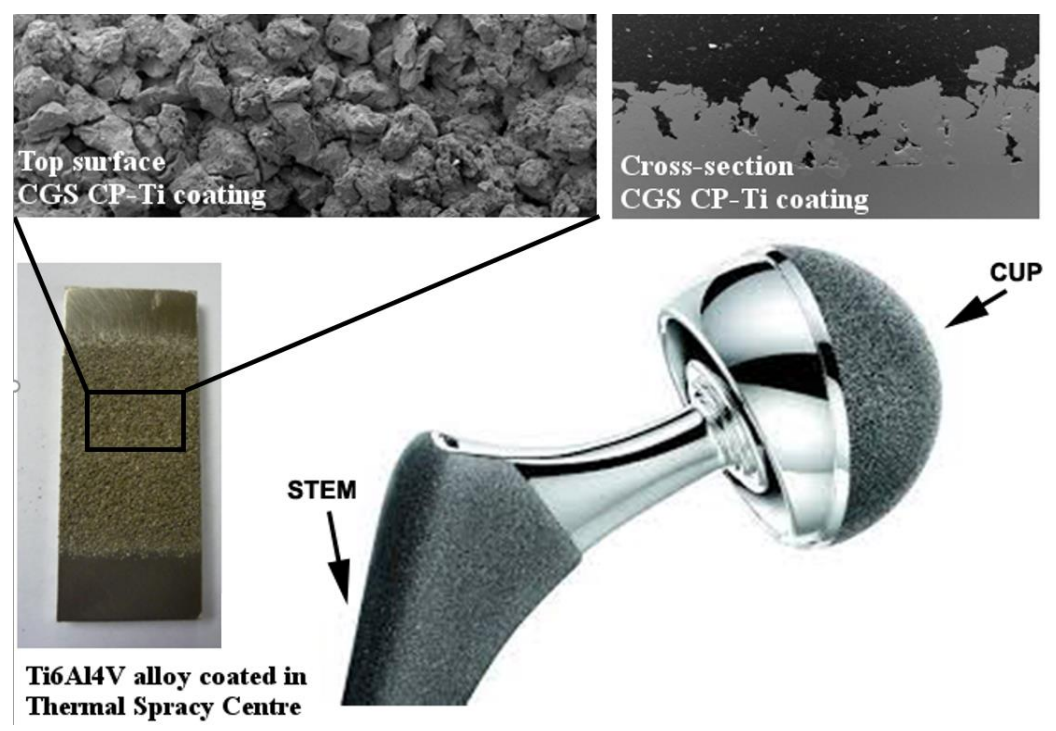

Figure 1. Illustrative schema of CGS CP-Ti coatings onto Ti6Al4V alloy substrate and hip prosthesis. Magnified details show the top surface and cross-section area of the optimized CGS CP-Ti coating [28].

To check that no bulk oxidation was produced during spraiyng and there are no problems to funcionalize the CGS CP-Ti coating, XRD from the CP-Ti powder and coatings were obtained (Fig. 2a), as well as the XPS spectra of the as-sprayed surface and after 2 min of Ar sputter-cleaned (Fig. 2b).

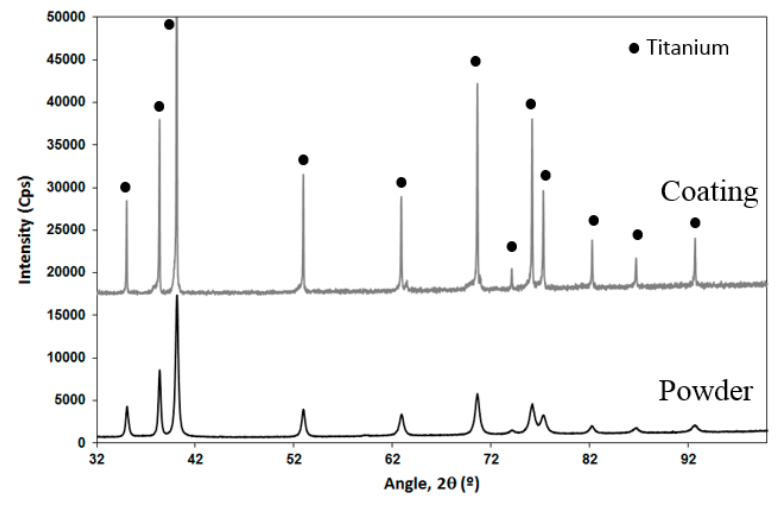

(a)

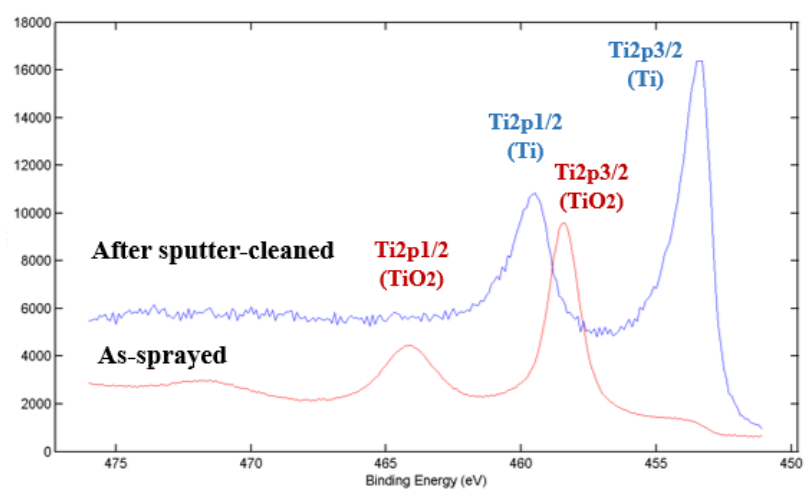

(b)

Figure 2. (a) XRD spectrums of CP-Ti powder and CGS CP-Ti coatings; (b) XPS spectrums of high-resolution Ti peaks of as-sprayed (red) and after sputter-cleaned (2min Ar) (blue) of CGS CPTi coatings. 
XRD spectra from the Ti powder and the CGS CP-Ti coatings show the same pure titanium pattern (Fig. 2a). In addition, high-resolution XPS Ti (Ti 2p1/2 and Ti 2p3/2) spectra of CGS CP-Ti coatings show $\mathrm{TiO}_{2}$ peaks at 464.16 and 458.42 for the as-sprayed coating (native $\mathrm{TiO}_{2}$ layer), and $\mathrm{Ti}(0)$ peaks at $459.53 \mathrm{eV}$ and $453.4 \mathrm{eV}$ after 2 min of Ar sputtering (Fig. 2b). These results show that bulk oxidation was not produced during spraying and only a thin $(2-10 \mathrm{~nm})$ spontaneously formed oxide layer appears on the CGS CP-Ti coating after the process [29].

\subsection{Mechanical characterization of CGS CP-Ti coatings}

The standard test method for adhesion was applied following ASTM C-633 for the evaluation of coating adherence. The strength value obtained from CP-Ti coatings by CGS is

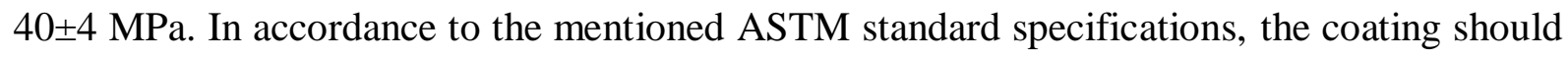
overcome the $20 \mathrm{MPa}$ ASTM F-2068 and ASTM F-2083. The coating failure mode was mainly cohesive.

Figure $3 \mathrm{a}$ shows a general view of the surface fracture section of the coating. It appears that the coating has mainly failed at particle-particle interfaces through decohesion. Further magnification reveals the presence of particles that have been deposited with quite extensive plastic deformation (Fig. $3 b$ and $3 c$ ). The features like in figure $3 b$ reveal the high level of material flow at interfaces when shear stresses take place upon impact. 

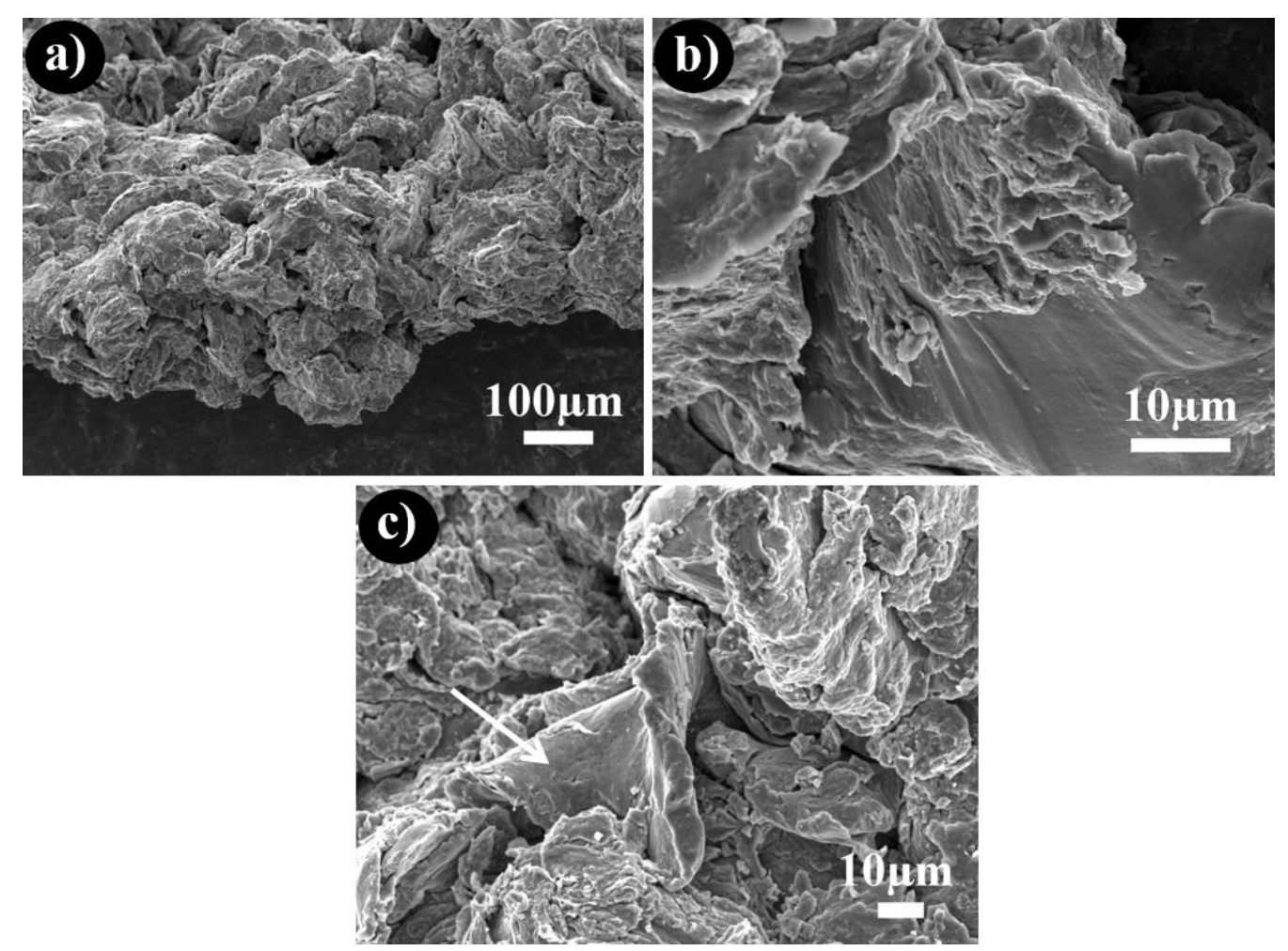

Figure 3. Fracture surface of CGS CP-Ti coatings: a) general view and b-c) higher magnification of deformed particles ductile features.

In addition, shear testing was performed. From the five specimens tested, a mean value of $39 \pm 2 \mathrm{MPa}$ was obtained, overcoming the $20 \mathrm{MPa}$ required from ASTM F-1044. A low scattering of the values was found due to the good bonding strength between the coating and the substrate. The fracture type was cohesive.

For the abrasive test, six specimens were tested according to ASTM F-1978 resulting in a mean loss mass of $37 \pm 4 \mathrm{mg} / 100$ cycles. Figure 4 shows SEM micrographs of the wear track after the Taber abrasion test. They reveal abrasive wear mechanism as observed with the scratch wear scars on the top asperities of the coating. 


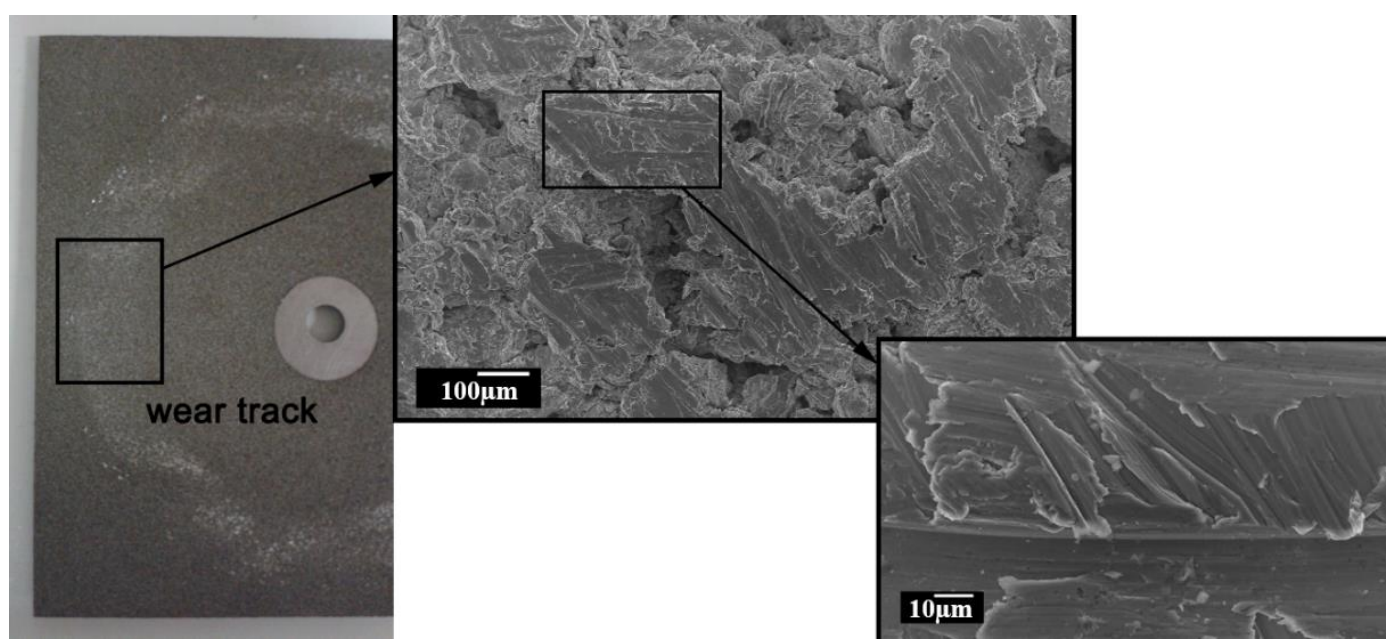

Figure 4. Free surface of CGS CP-Ti coating after Taber abrasion test and SEM micrograph details of the wear track.

\subsection{Functionalization by anodizing}

Taking into account the relevance of the surface structure and composition on the properties and performance of Ti materials, nano-structures were obtained on the CGS CP-Ti coatings by anodizing in ethylene glycol-based electrolytes. Using this approach, new hierarchical coatings with a top $\mathrm{TiO}_{2}$ NTs layer with controlled diameter were obtained. However, it is well known that it is difficult to obtain useful clean NT's surfaces in the anodizing process of $\mathrm{Ti}$ due to the remaining compact oxide layer formed in the initial steps of the process. Figure 5a shows the typical structure obtained without an accurate control of anodizing conditions on smooth Ti surfaces. A double anodizing process on smooth foils has been usually applied to minimize the presence of such compact oxide layer (Fig. 5b) [30]. However, the difficulty to etch the first anodic layer on the CGS CP-Ti surface prevents the application of this approach. Therefore, the conditions needed to obtain the cleanest surfaces in single anodizing processes were obtained on controlled smooth $\mathrm{Ti}$ and CGS CP-Ti substrates. $30 \mathrm{~V}-2700$ s or $40 \mathrm{~V}-1800$ s are experimental conditions that allow us to optimize the surface morphology, on both smooth Ti foil and CGS CP-Ti surface: a NTs layer with 30-100 $\mathrm{nm}$ pore diameter was obtained (Fig. 5c) in a single anodizing step. 

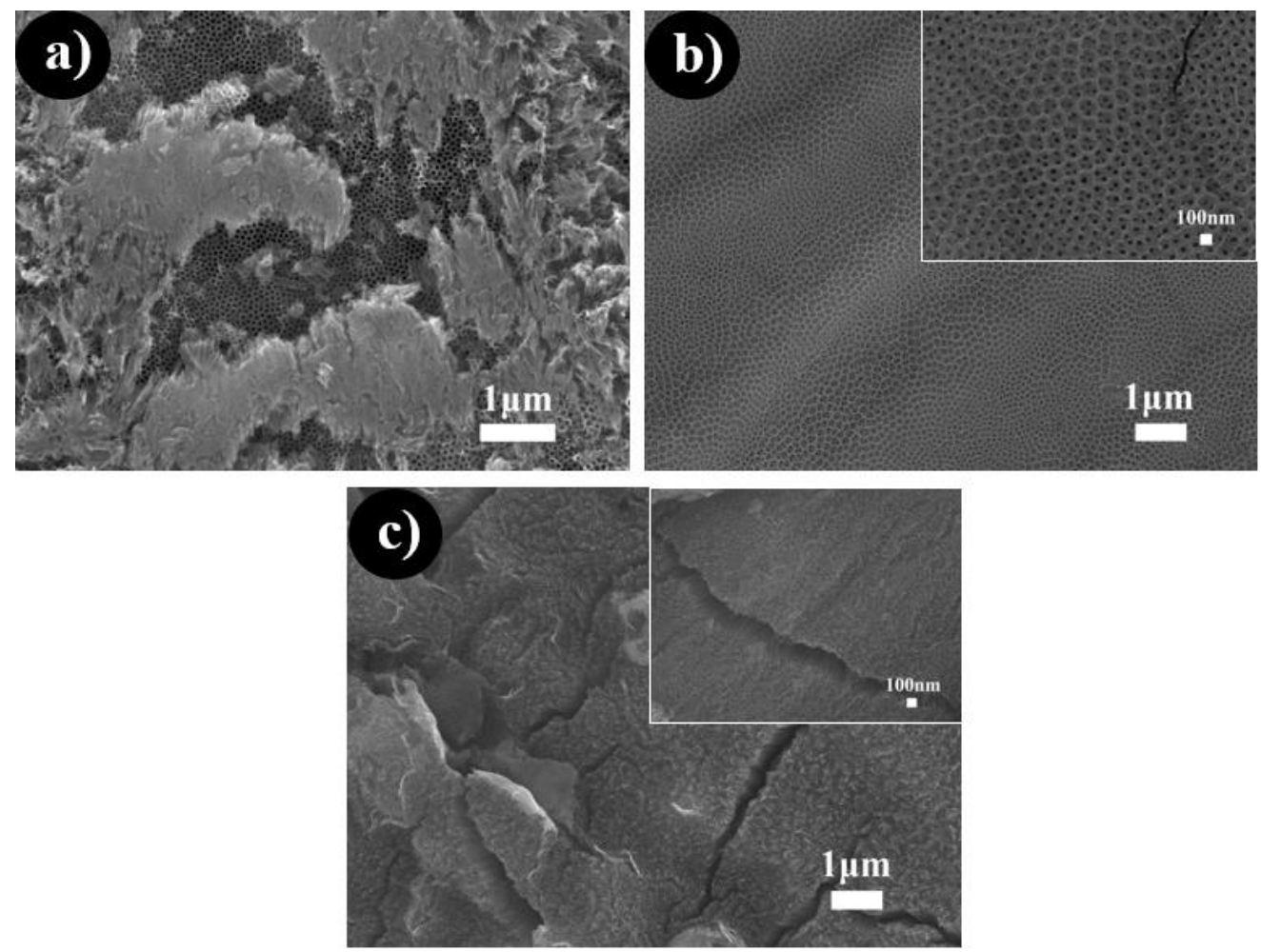

Figure 5. FESEM images of the optimization of $\mathrm{TiO}_{2}$ NTs layer: a) non accurate single anodized process at $30 \mathrm{~V}-1200 \mathrm{~s}$; b) double anodized process onto smooth Ti foil: first step: 60V-900s, second step: 40V-900s with magnification (inset); and c) single anodized process onto CGS CP-Ti coating at 30V-2700s with magnification (inset).

\subsection{Roughness}

Table 1 and figures 6 and 7 show the 2D and 3D roughness and microroughness values of different analyzed samples, including functionalized smooth Ti foil samples as a reference. Figure 6 includes the 3D profile of the analyzed samples and figure 7 the $2 \mathrm{D}$ profile of the CGS CP-Ti coatings and after their anodization at 30V-2700s, showing the contribution of the filtered waviness and microroughness profile. It is interesting to remark that the anodizing process of the Ti surface increases slightly the 2D and 3D roughness of the smooth Ti foil, but decreases the 2D of the CGS CP-Ti surface. 
Table 1. Global profile, $2 \mathrm{D}$ and $3 \mathrm{D}$ roughness filtered $(\mu \mathrm{m})$ of analyzed samples.

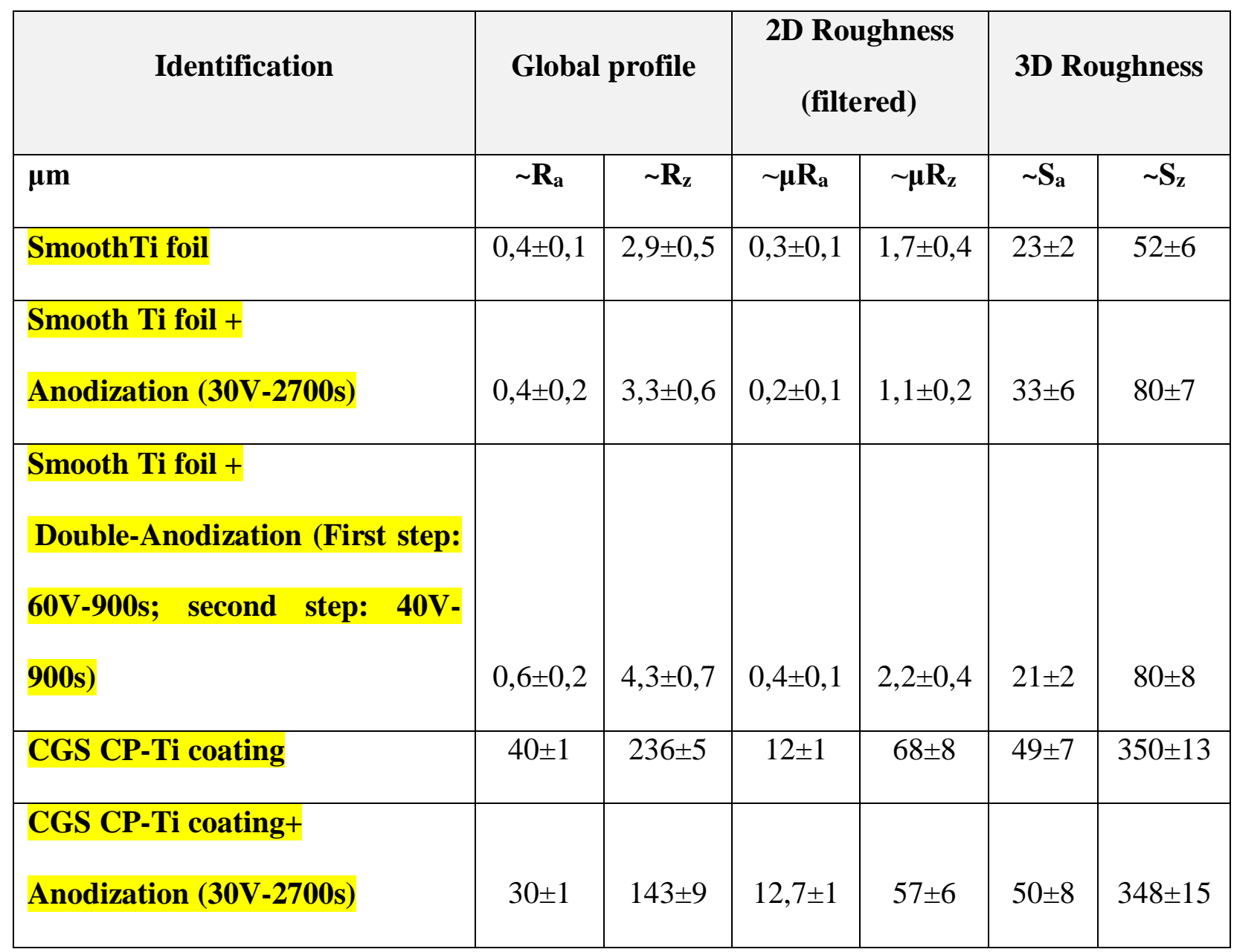



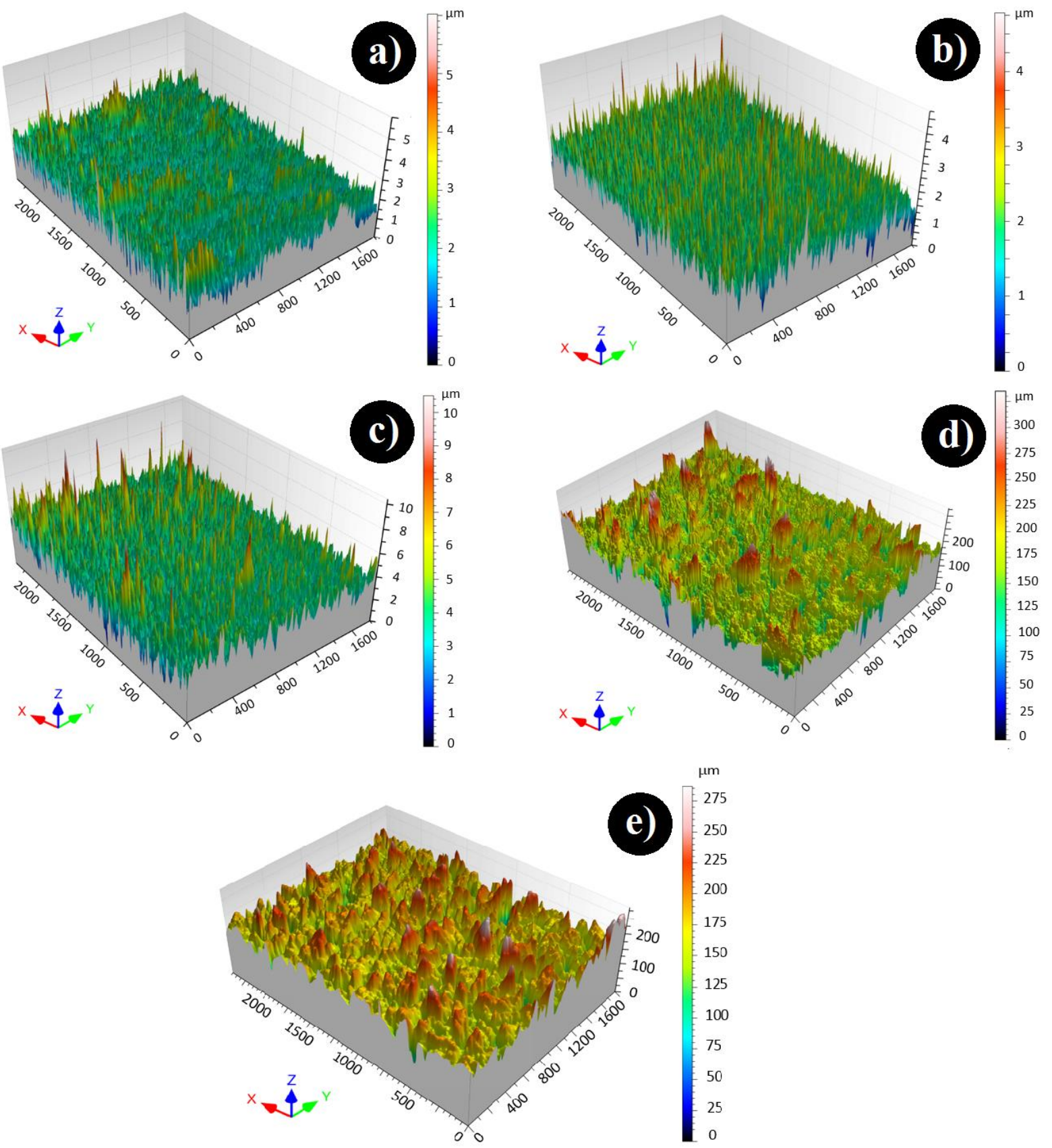

Figure 6. 3D microroughness patterns of the a) smooth Ti foil, b) anodized Ti foil (30V2700s) and c) double anodized Ti foil (first-step: 60V-900s; second-step:40V-900); d) assprayed CGS CP-Ti coating and (e) after anodization at 30V-2700s. 

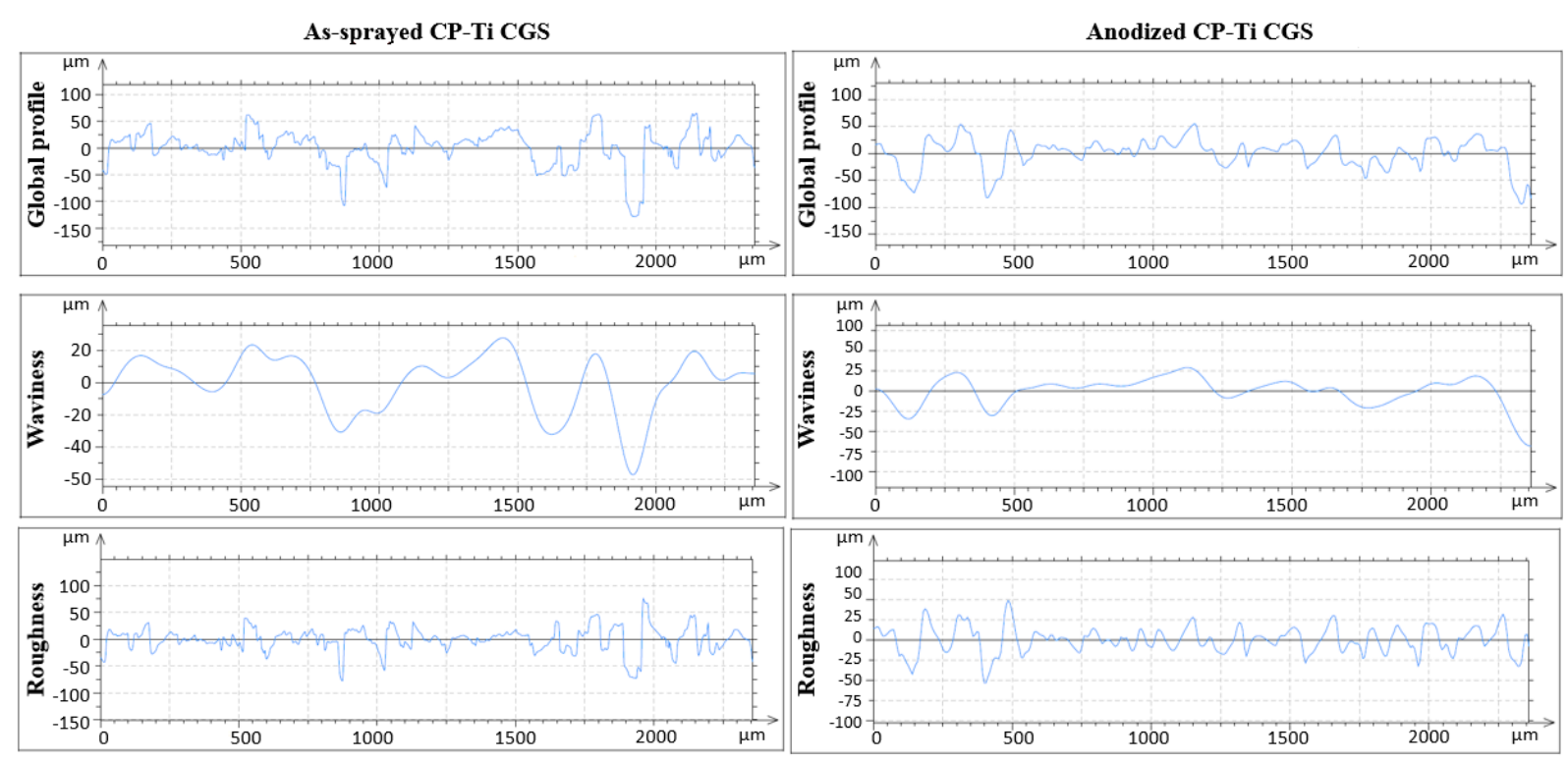

Figure 7. 2D Global profile divided into waveness and roughness patterns of as-sprayed CGS

CP-Ti coatings (left) and after anodic oxidation treatment 30V-2700s (right).

\subsection{Wettability behavior intended for biomedical applications}

Table 2 shows the contact angles measured for the as-sprayed coating and the smooth Ti foil samples. As prepared, anodized (CGS CP-Ti coating and smooth Ti foil) and double anodized (smooth Ti foil) samples were analyzed.

Table 2. Values of the contact angles of as prepared and anodized samples with and without.

NTs presence.

\begin{tabular}{|l|c|}
\hline Identification & Contac tangle $\mathbf{(}^{\mathbf{}}$ ) \\
\hline Smooth Ti foil & $73 \pm 2$ \\
\hline Smooth Ti foil + Anodization (30V-2700s) & $20 \pm 4$ \\
\hline Smooth Ti foil + Double-Anodization: (First & \\
step: 60V-900s; second step: 40V-900s) & $67 \pm 6$ \\
\hline CGS CP-Ti coating & $26 \pm 10$ \\
\hline CGS CP-Ti coating +Anodization (30-2700s) & 0 \\
\hline
\end{tabular}


The smooth Ti sample showed a hydrophobic behavior with a contact angle near to $70^{\circ}$ but, as can be expected according to the roughness values, the as-sprayed sample reduces the contact angle to $50^{\circ}$. In addition, in any case, the simple anodized samples increase the hydrophilic behavior with respect to the non-anodized ones. However, while the contact angle is reduced to less than $20^{\circ}$ for the anodized smooth Ti foil, super-hydrophilicity (contact angle $\left.0^{\circ}\right)$ was observed for the anodized CGS samples (Fig. 8). These results show that the rough surface with the presence of NTs increased wettability to the maximum level [31]. Many authors have actually observed the reduction of the contact angle in Ti treated surfaces, which leads to high surface energy and affects cell adhesion, spreading and growth [32].
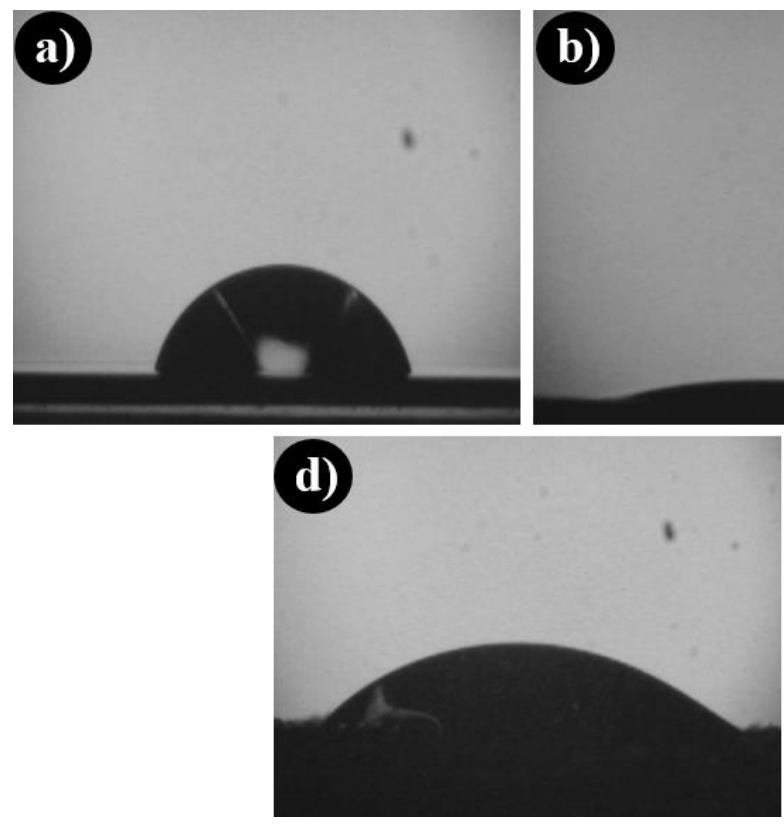
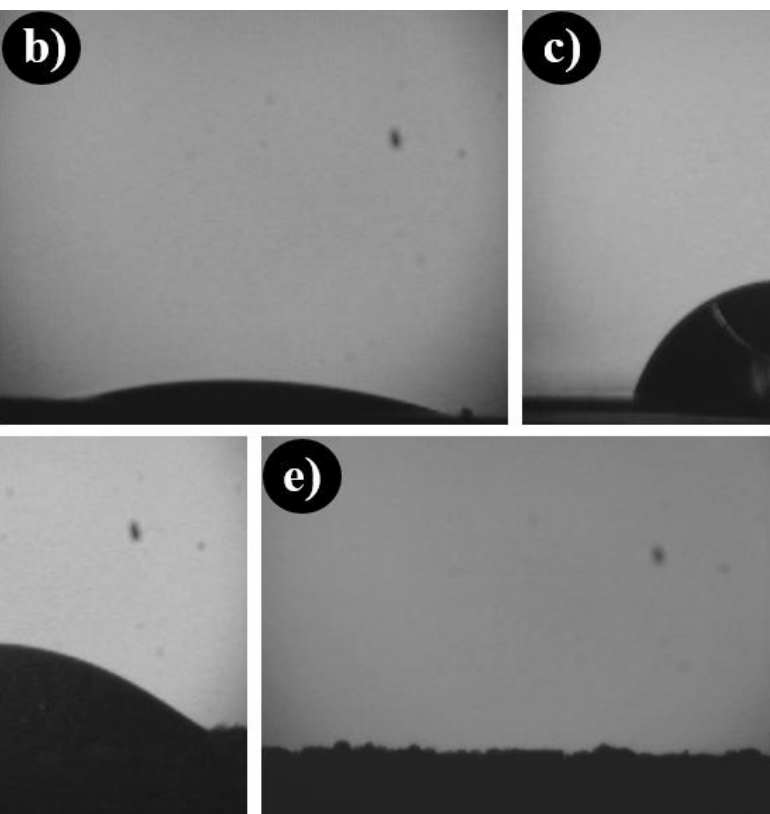

Figure 8. Contact angle images Milli-Q $\mathrm{H}_{2} \mathrm{O}$ droplet of: a) smooth Ti foil , b) anodized Ti foil (30V-2700s) and c) double anodized Ti foil (first-step: and 60V-900s; second-step:40V-900); d) as-sprayed CGS CP-Ti coating and e) after anodization at 30V-2700s.

It is noteworthy also that double anodized samples show an increase of hydrophobicity, directly related to the double structure of the cells observed in the surface of the porous structure (Fig. 5e). This structure is fixed by the geometry defined in the first anodizing step. 


\section{Discussion}

Vacuum Plasma Spraying is the current most stablished commercial technology to produce porous and rough metallic titanium coatings for biomedical purposes, although other options have also been investigated [33]. CGS CP-Ti provides low-cost free oxide coatings with good mechanical properties values according to ASTM Standards, as well as better control of the composition of the sprayed structure and surface topography. Large irregular sized Ti particles were used in the CGS deposition processes to achieve porous rough coatings (up to $\mathrm{Ra} \approx 40 \mu \mathrm{m}$ ) with controlled mechanical performance. This is more feasible than using small particles due to their lower velocities and wider gaps to be filled between the deposited particles during spraying $[7,34]$. The use of coarse particles in CGS has been used however in very few occasions in the past [6]. Actually, to produce controlled porosity in titanium coatings by CGS, some porogen elements have been reported in the literature, such as magnesium, reaching porosities of $\sim 48 \%$ and pore sizes in the range of 70 to $150 \mu \mathrm{m}$ [35] or aluminum with pore percentage between $48-66 \%$ and pore size $74-91 \mu \mathrm{m}$ [36]. Therefore, rough $\mathrm{CP}-\mathrm{Ti}$ coatings by $\mathrm{CS}$ did not show the presence of oxide after the spraying (Fig. 2a). However, the detection of a spontaneous thin of $\mathrm{TiO}_{2}$ layer by XPS was attributed to surface passivation due to its thickness of 2-10 $\mathrm{nm}$ (Fig. 2b).

The optimal porous and rough coating here achieved, reaches a mean tensile strength of $40 \pm 4 \mathrm{MPa}$ and shear strength of $39 \pm 2 \mathrm{MPa}$ with an adhesive failure. Compared to other thermal spray techniques, VPS reaches tensile and shear strength values of $40 \mathrm{MPa}$ with porosities between 20-60\% [37], but, in certain conditions, $60 \mathrm{MPa}$ can be achieved by CGS for titanium coatings [38]. The increasing of particle size leads to a decrease in mechanical properties but an increase in roughness. The fracture surface of CGS CP-Ti coatings shows extended plastic deformation of the particles before fracture. The failure appears to be through decohesion at the few contact points at particle boundaries. The fibrous appearance of the 
surface showed the extensive plastic deformation of the particles upon impact. The material "pulled apart" leaving a rough surface, thus a slow crack propagation and absorption of a large amount of energy before the fracture (Fig. 3). In addition, Taber abrasion test shows similar results of CGS CP-Ti coatings and VPS-Ti coatings, resulting in a $37 \pm 4 \mathrm{mg}$ and $31 \pm 12 \mathrm{mg}$ respectively [39]. The wear track surface reveals an abrasive wear mechanism. Two-body abrasion occurs when the asperity of the wheel contacts the CP-Ti coating surface. Non-particle detachment between both surfaces is severely perceived [40]; rather, scratching is produced on the top of the asperities and would progressively promote levelling of those asperities reducing the surface roughness although in view of the obtained results this would occur at very slow rates (Fig. 4).

The anodizing approach has been mainly applied to rough surfaces to improve the surface wettability with the aim to facilitate cell attachment in biomedical applications. Table 2 as well figure 8 reflect that phenomenon. The anodization of smooth Ti foils let to higher wettability, as well as on CGS CP-Ti coatings; although the microroughness is slightly decreased after anodic oxidation treatment onto CGS CP-Ti coatings, it is maintained high $(\mathrm{Ra} \approx 30 \mu \mathrm{m})$ with high free surface area do to the nanotexturment of $\mathrm{TiO}_{2} \mathrm{NT}$ s layer (Table 1): a high surface energy and high topography of titanium modified surfaces, by treatments such as acid-etching, show that both micron-scale and submicron scale structural features are necessary [41]. The production of hierarchical structures is promising [42] but the exact role played by the micro- or nano-topographies needs more studied.

Y. Xie et al. [22] performed an anodization of vacuum plasma spray titanium coatings deposited on Ti-6Al-4V alloy substrates, and found higher cell adhesion quantity (about 30\% more) on the hierarchical structure than that on the as-sprayed VPS coatings. Also, Hall et al. [43] anodized Ti6Al4V beads sintered to a Ti6Al4V hip stem substrate; it was clinically 
proved that when the femoral implants were inserted to dogs, they improved of bone ingrowth and implant integration, as well as the decrease of fibrous tissue was achieved.

The current anodizing conditions lead to a NT diameter of 30-100 nm (Fig. 5c); these are values in accordance with the ones described in previous analysis of cell integration [44]. Minagar et al. [45] listed the different works reporting cell responses to various $\mathrm{TiO}_{2} \mathrm{NTs}$ on Ti ranging from $15-30 \mathrm{~nm}$ to $70-100 \mathrm{~nm}$. It should be here remarked that anodizing such an irregular surface makes more difficult to avoid the presence of the compact oxide layer than when compared to a titanium smooth foil.

In terms of biological properties, CGS CP-Ti coatings provide higher free surface area, but also surface wettability due to its topography, both ideal for cell deposition and cell response. However, the performance of $\mathrm{TiO}_{2}$ NTs onto CGS CP-Ti coatings acts as a barrier against metal ion release and provides superhydrophilic behavior due to the surface nanofeatures but also its composition of titanium oxide [46]. $\mathrm{TiO}_{2} \mathrm{NTs}$ have been demonstrated to promote cell adhesion thus cell proliferation and differentiation, and decrease bacterial adhesion $[11,47]$.

To sum up then, the present use of the CGS technology with superimposed anodizing results in good mechanical performance and superhydrophilic surfaces; this can be foreseen as a new route to produce micro-/nano hierarchical surfaces that need to be revised under in vitro and in vivo conditions.

\section{Conclusions}

- Cold Gas Spray has demonstrated to be a suitable technique to produce porous pure titanium coatings for medical purposes in prosthetic applications. The evaluation of such coatings indicates that the process can become competitive to the currently established VPS method with cost effective characteristics. 
- According to ASTM standard specifications for hip, knee and shoulder joint prosthesis applications, the selected CGS CP-Ti coating overcome with all mechanical requirements with $40 \pm 4 \mathrm{MPa}$ of tensile strength, $39 \pm 2 \mathrm{MPa}$ of shear strength and $37 \pm 4$ mg/100 cycles of loss weigh in abrasive test. The hydrophilicity of the CGS CP-Ti surface coating is noticeably increased compared to a smooth foil. Controlled anodizing was successfully applied to functionalize such coating surfaces to obtain a layer of anatase $\mathrm{TiO}_{2}$ nanotubes. The increase of hydrophilicity favors cell attachment thus cell response. Therefore, nanostructurated surfaces enhances biological properties such as cell proliferation and differentiation.

\section{Acknowledgements}

The authors want to thank the Spanish MINECO and the European regional development fund (ERDF) for financial support through project MAT2013-46755-R, and the Generalitat de Catalunya for the project 2014 SGR 1558, and University of Barcelona for the award of a scholarship that has helped the development of this research.

\section{References}

[1] A. Moridi, SM. Hassani-Gangaraj, M. Guagliano and M. Dao: Surf. Eng., 2014, 30, 369395.

[2] T. Hussain, DG. McCartney, PH. Shipway and T. Marrocco: J. Therm. Spray Tech., 2011, 20, 260-274.

[3] G. Bae, S. Kumar, S. Yoon, K. Kang, H. Na, H-J. Kim and C. Lee: Acta Mater.,2009, 57, $5654-5666$.

[4] SH. Zahiri, CI. Antonio and M. Jahedi: J. Mater. Process. Tech., 2009 209, 922-929. 
[5] X-T. Luo, C-X. Li, F-L. Shang, GJ. Yang, YY. Wang, CJ. Li: Surf. Coat. Tech., 2014, $254,11-20$.

[6] TH.Van Steenkiste, JR. Smith and RE. Teets: Surf. Coat. Tech., 2002, 154, 237-252.

[7] T. Schmidt, F. Gärtner, H. Assadi and H. Kreye: Acta Mater., 2006, 54, 729-742.

[8] D. Lakstein, D. Backstein, O. Safir, Y. Kosashvili and AE. Gross: Clin. Orthop. Relat. Res., 2010, 468, 1310-1315.

[9] SL. Barnett, RR. Mayer JS. Gondusky, L. Choi, JJ. Patel and RS. Gorab: J. Arthroplasty, 2014, 29, 1219-1224.

[10] M. Salemyr, O. Muren, T. Eisler, H. Bodén, G. Chammout, A. Stark and O. Sköldenberg: Int. Orthop., 2014, 39, 823-832.

[11] H. Jeon, CG Jr Simon, G. Kim. J. Biomed. Mater. Res., 2014, 102A, 1580-1594.

[12] J. Yul Lim and HJ. Donahue: Tissue Eng., 2007, 13, 1879- 1891.

[13] C. HoJun Jeon, G. Simon and K. Geun Hyung: J. Biomed. Mater. Res. B Appl. Biomater., 2014, 102B:7, 1580- 1594.

[14] V. Borsari, G. Giavaresi, M. Fini, P. Torricelli, M. Tschon, R. Chiesa, et al.: Biomater., 2005, 26, 4948-4955.

[15] S. Endres, M. Wilke, P. Knöll, H. Frank, M. Kratz and A. Wilke: J. Mater. Sci. Mater. Med., 2008, 19, 1117-1125.

[16] JY. Martin, Z. Schwartz, TW. Hummert, DM. Schraub, J. Simpson, J Jr. Lankford, DD. Dean, DL. Cochran and BD. Boyan: J. Biomed. Mater. Res., 1995, 29, 389-401.

[17] Y. Xie, H. Ao, S. Xin, X. Zheng, C. Ding. Mater. Sci. Eng. C, 2014, 38, 272-277.

[18] BS. Kang, YT. Sul, HJ. Lee and T. Albrektsoon: Acta Biomater., 2009, 5:6, 2222-2229.

[19] A. Verket, H. Tiainen, HJ. Haugen, SP. Lyngstadaas, O. Nilsen and JE. Reseland: Biointerphases, 2012, 7, 1-10. 
[20] K. Liu, M. Cao, A. Fujishima and L. Jiang: Chem. Rev., 2014, 114 10044-10094.

[21] S. Oh, C. Daraio, LH. Chen, TR. Pisanic, RR. Fiñones and S. Jin: J. Biomed. Mater Res. A, 2006, 78A, 97-103.

[22] Y. Xie, H. Ao, S. Xin, X. Zheng and C. Ding: Mater. Sci. Eng. C, 2014, 38, 272-277.

\section{[23] T. Tian, H. Dong, X. Tian and Y. Hao; J. Saf. Sci. Technol., 2013, 3, 59-62.}

[24] M. Lorenzetti, I. Dogša, T. Stošicki, D. Stopar, M. Kalin, S. Kobe and S. Novak: App. Mater. Interfaces, 2015, 7, 1644-1651.

[25] R. Narayan, S. Bose and A. Bandyopadhyay: Drug delivery from Surface modified titanium alloy for load-bearing implants, Biomaterials Science: Processing, Properties and Applications V, Ceramic Transactions, Vol 254, John Wiley \& Sons, 2015 - 208 pp

[26] D. Losic, M. Sinn Aw, A. Santos, K. Gulati and M. Bariana: Expert Opin. Drug Deliv., $2015,12,103-127$.

[27] Intelectual Property: JM. Guilemany, N. Cinca, S. Dosta, I. Garcia-Cano, Feasibility of cold gas spraying to produce high roughness high porous titanium coatings for metallic prosthesis, Ref Number 1870. Universitat de Barcelona. Legal Deposit: 17/10/2014, Spain, 2014.

[28] Biomet M2a hip replacement: http://www.wynnandwynn.com/blog/biomet-m2a-hip/.

\section{Accessed 20 November 2017.}

[29] EP. Lautenschlager and P. Monaghan: I. Dent J., 1993, 43, 245-53.

[30] GD. Sulka, J. Kapusta-Kolodziej, A. Brzózka and M. Jaskula: Electrochem Acta, 2010, $55,4359-4367$

[31] JL. Rosa, RZ. Nakazato, SG. Scheneider, AP. Alves Claro and MC. Albes Rezende: Arch. Health Invest., 2014, 3, 43-47. 
[32] S. Bauer, J. Park, K. Von der Mark and P. Schmuki: Acta Biomater., 2008, 4, 15761582.

[33] RM. Wazen, LP. Lefebvre, E. Baril and A. Nanci: J. Biomed. Mater. Res. B Appl.

Biomater., 2010, 94, 64-71.

[34] N. Cinca, JM. Rebled, S. Estradé, F. Peiró, J. Fernández and JM. Guilemany: J. Alloy Comp., 2013, 554, 89-96.

[35] J. Sun, Y. Han and K. Cui: Mater. Lett., 2008, 62, 3623-3625.

[36] D. Qiu, M. Zhang and L. Grøndahl: J. Biomed. Mater. Res. A, 2013, 101, 862-872.

[37] Coating research and developing IT. VPS Titanium Coatings.

http://www.eurocoating.it/plasma_spray_coatings/vacuum_plasma_spray_titanium_coatings/ default.aspx. Accessed 22 March 2017.

[38] M. Gardon, C. Concustell, S. Dosta, N. Cinca, IG. Cano and JM. Guilemany: Mater. Sci.

Eng. C, 2014, 45:117-121

[39] Titanium Plasma Spray https://www.exac.com/resource-library/hip/referencepapers/titanium-plasma-spray file. Accessed 31 May 2017.

[40] HA. McKellop, A. Hart, S-H. Park, H. Hothi, P. Campbell and JA. Skinner: J. Orthopaedic Res., 2014, 32, 1221-33.

[41] G. Zhao, AL. Raines, M. Wieland, Z. Schwartz and BD. Boyan, B.D: Biomater., 2007 $28,2821-2829$.

[42] H. Jeon, CG Jr. Simon and G. Kim: J. Biomed Mater. Res. B Appl. Biomater., 2014, 102, $1580-1594$.

[43] DJ. Hall, RM. Urban, R. Pourzal, TM. Turner, AK. Skipor and JJ. Jacobs: J. Biomed. Mater. Res B Appl. Biomater., 2014, 105, 283-290.

[44] Z. Xu Y. Lai, D. Wu, W. Huang, S. Huang, L. Zhou and J. Chen: Biomed. Res. Int., 2015, 2015, 9p 
[45] S. Minagar, J. Wang, CC. Berndt, EP. Ivanova and C. Wen: J. Biomed. Mater. Res. A, 2013, 101A, 2726-2739.

[46] KS. Brammer, S. Oh, CJ. Cobb, LM. Bjursten, H. van der Heyde and S.Jin: Acta Biomater., 2009, 5, 3215-3223.

[47] B. Ercan, E. Taylor, E. Alpaslan and TJ. Webster: Nanotechnol., 2011, 22, 295102. 